\title{
$\mathbf{J}|\mathbf{A}| \mathbf{C} \mid \mathbf{S}$ \\ COMMUNICATIONS
}

Published on Web 02/05/2002

\section{New Phosphate Fluorosurfactants for Carbon Dioxide}

\author{
Jason S. Keiper, Ruma Simhan, and Joseph M. DeSimone* \\ NSF Center for Environmentally Responsible Solvents and Processes, Department of Chemistry, \\ University of North Carolina at Chapel Hill, Chapel Hill, North Carolina 27599, and Department of \\ Chemical Engineering, North Carolina State University, Raleigh, North Carolina 27695 \\ George D. Wignall* and Yuri B. Melnichenko \\ Solid State Division, Oak Ridge National Laboratory, ${ }^{\S}$ Oak Ridge, Tennessee 37831 \\ Henrich Frielinghaus \\ Forschungszentrum Jülich GmbH, Institut für Festkörperforschung, D-52425 Jülich, Germany
}

Received September 21, 2001

The vast potential of carbon dioxide $\left(\mathrm{CO}_{2}\right)$ as an environmentally clean, abundant, and tunable solvent is now being realized on a variety of fronts, including cleaning protocols in microelectronics and garment care industries, coatings, and polymer production and processing. ${ }^{1}$ To take advantage of $\mathrm{CO}_{2}$ 's benefits, however, it is often necessary to confront an important limitation, namely its low capacity for solubilizing many materials, including water. ${ }^{2}$ One way this issue has been addressed is through the use of small-molecule fluorosurfactants to aid the dispersion of water-in- $\mathrm{CO}_{2}(\mathrm{~W} / \mathrm{C}){ }^{3}$ Unfortunately, only a handful of surfactants have proven capable of water uptake in neat $\mathrm{CO}_{2}$. Here, we report initial findings on chemically homogeneous anionic phosphate fluorosurfactants that enable significant water uptake within a continuous $\mathrm{CO}_{2}$ phase, through the formation of W/C microemulsions without the aid of a cosurfactant. ${ }^{4}$ The double-tailed surfactants are of two general structural types: a form containing two fluorinated chains (1) and a "hybrid" form ${ }^{3 a}$ containing one fully hydrocarbon chain and one fluorinated chain (2). Two such surfactants, which can be prepared in a straightforward manner in high purity, ${ }^{5}$ are shown below.

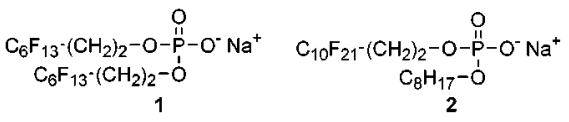

Ionic solutes generally possess low solubility in compressed $\mathrm{CO}_{2}{ }^{2}$ This was indeed the case for surfactant $\mathbf{1}$, which was insoluble at $1 \mathrm{wt} \%$ at temperatures from 25 to $65{ }^{\circ} \mathrm{C}$ and pressures up to 380 bar. ${ }^{6}$ Surfactant 2 proved soluble at 1 wt $\%$ under rather mild pressures (for example, cloud points at 60 and $27{ }^{\circ} \mathrm{C}$ occurred at 225 and 119 bar, respectively). It is not clear why the hybrid surfactant $\mathbf{2}$ has such appreciable "dry" solubility in $\mathrm{CO}_{2}$, although self-assembly into reverse micelles, perhaps with internal cores incorporating the hydrocarbon chain, is one possibility. Addition of water to either surfactant in $\mathrm{CO}_{2}$ allowed for the formation of clear, single-phase solutions. Cloud point profiles of $2.5 \mathrm{wt} \%$ surfactant solutions in $\mathrm{CO}_{2}$ with varied water/surfactant molar ratios $\left(W_{\mathrm{o}}\right)^{7}$ are shown in Figure 1, where homogeneous solutions existed at pressures above the curves and heterogeneous, phase-separated solutions existed below the curves. For surfactant $\mathbf{1}$, the cloudpoint behavior followed essentially linear trends for water loadings spanning from $W_{\mathrm{o}}=11$ up to at least 45 (for $W_{\mathrm{o}}=45$ there were equivalent weights of water and surfactant). The cloud-point

* To whom correspondence should be addressed.

\& Managed by UT-Battelle, LLC under contract DE-AC05-00OR22725 with the U.S. Department of Energy.
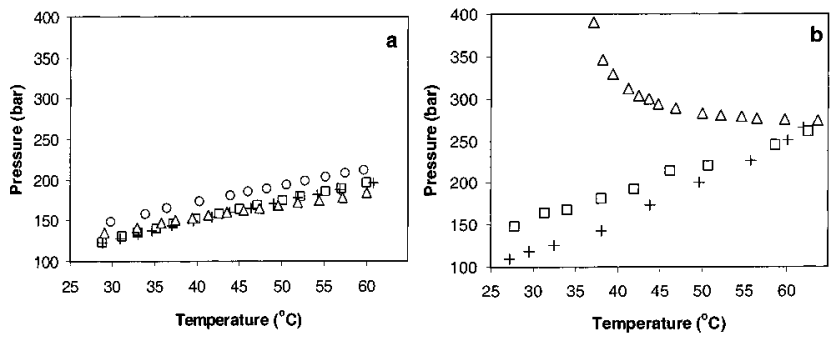

Figure 1. Cloud-point profiles of phosphate fluorosurfactants $(2.5 \mathrm{wt}$. \%) in $\mathrm{CO}_{2}$ at various water loadings. The solutions are one phase at pressures above the curves and phase-separated at pressures below the curves. (a) Surfactant $1(\triangle) W_{\mathrm{o}}=11 ;(+) W_{\mathrm{o}}=17 ;(\square) W_{\mathrm{o}}=36$; (O) $W_{\mathrm{o}}=45$. (b) Surfactant $2(\triangle) W_{\mathrm{o}}=11 ;(+) W_{\mathrm{o}}=17 ;(\square) W_{\mathrm{o}}=34$.

pressure ranges observed here were comparable to those determined for W/C microemulsion-forming fluorosurfactants at similar temperatures and concentrations (Figure 1a). ${ }^{3}$ The phase behavior for surfactant 2 was not straightforward. At $W_{0}=11$, cloud-point pressures curved upward as temperatures decreased, while for $W_{\mathrm{o}}$ $=17$ and 34, cloud-point pressures decreased rather linearly (Figure 1b). Opposite trends were recently reported for a cationic perfluoropolyether surfactant in $\mathrm{CO}_{2} \cdot{ }^{8}$ Considering the high analytical purity of the surfactant and the reproducibility of the cloud-point measurements $( \pm 0.5$ bar), we speculate that this unusual phase behavior is related to a change in aggregate morphology, perhaps from spherical assemblies to cylinders, as a consequence of the hybrid chains present in surfactant 2 .

While cloud-point measurements indicate phase boundaries of the W/C systems, additional evidence is necessary to definitively prove microemulsion formation. Aqueous domains in the surfactant/ water/ $\mathrm{CO}_{2}$ solutions were revealed through the use of the solvatochromatic probe methyl orange (MO). ${ }^{3 b, 8-10} \mathrm{MO}$ does not dissolve in pure $\mathrm{CO}_{2}$, but can be dispersed within the water-rich pockets of microemulsion aggregates, with its wavelength maximum $\left(\lambda_{\max }\right)$ dependent upon the local polarity. Previous studies on perfluoropolyether carboxylate surfactants showed $\lambda_{\max }$ increased with higher water loadings, as the dye presumably resided in environments that progressively approached the polarity of bulk water (MO in pure water $\left.\lambda_{\max }=464 \mathrm{~nm}\right){ }^{3 \mathrm{~b}}$ Similar behavior was seen here for surfactant 1 (275 bar, $25^{\circ} \mathrm{C}$; [surfactant] $=30 \mathrm{mM}$ or $2.5 \mathrm{wt} \%$; $[\mathrm{MO}]=0.05 \mathrm{mM})$. As $W_{\mathrm{o}}$ was increased from 7 to 12 to $17, \lambda_{\max }$ increased from 434 to 441 to $447 \mathrm{~nm}$, respectively (Figure 2). The presence of red-shifted shoulders at $\lambda>500 \mathrm{~nm}$ for the solutions with $W_{\mathrm{o}}=12$ and 17 is attributable to the acidic nature of the 


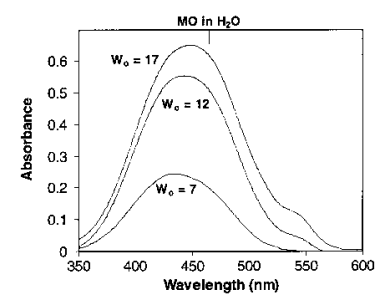

Figure 2. $\mathrm{UV}-$ vis spectra of $0.05 \mathrm{mM}$ methyl orange dispersed in $\mathrm{CO}_{2}$ solutions containing $30 \mathrm{mM}(2.5$ wt. \%) surfactant 1 with varied water loadings at $275 \mathrm{bar}$ and $25^{\circ} \mathrm{C}$. $\lambda_{\max }$ values: $W_{\mathrm{o}}=7: 434 \mathrm{~nm} ; W_{\mathrm{o}}=12$ : $441 \mathrm{~nm} ; W_{\mathrm{o}}=17: 447 \mathrm{~nm}$.
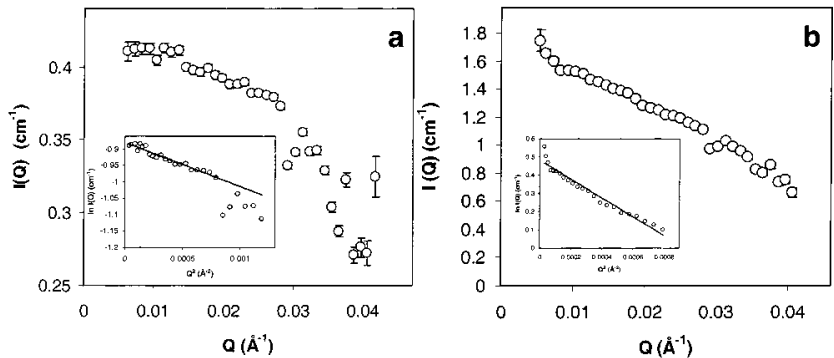

Figure 3. SANS profiles of (a) surfactant 1 ( $2.7 \mathrm{wt}$. $\%$ surfactant $\mathbf{1}, W_{\mathrm{o}}=$ 12,379 bar, $\left.24^{\circ} \mathrm{C}\right)$ and (b) surfactant 2 (6.3 wt. \% surfactant $2, W_{\mathrm{o}}=12$, $\left.317 \mathrm{bar}, 60^{\circ} \mathrm{C}\right)$. Corresponding Guinier plots are shown in the insets.

microemulsion water pools due to the presence of carbonic acid (MO in aqueous carbonic acid $\lambda_{\max }=502 \mathrm{~nm}$ ). ${ }^{3 \mathrm{~b}, 9}$

The presence of microemulsion water pools was directly confirmed using small angle neutron scattering (SANS). ${ }^{11}$ Measurements were made on one-phase solutions of $\mathrm{CO}_{2}$, surfactant and $\mathrm{D}_{2} \mathrm{O}$. Figure 3 depicts example SANS profiles for solutions of surfactant 1 ( $2.7 \mathrm{wt} \%$ surfactant $\left.\mathbf{1}, W_{\mathrm{o}}=12,379 \mathrm{bar}, 24^{\circ} \mathrm{C}\right)$ and surfactant 2 (6.3 wt $\%$ surfactant $2, W_{\mathrm{o}}=12,317 \mathrm{bar}, 60^{\circ} \mathrm{C}$ ). In the insets the data are shown in corresponding Guinier plots, from which $R_{\mathrm{g}}$ values of $26.7 \AA\left[I(0)=0.43 \pm 0.03 \mathrm{~cm}^{-1}\right]$ and $34.4 \AA$ $\left[I(0)=1.58 \pm 0.1 \mathrm{~cm}^{-1}\right]$ were determined. For surfactant $\mathbf{1}, R_{\mathrm{g}}$ is relatively independent of concentration and changes by $<10 \%$ as the surfactant concentration is increased from 2.7 to $5.3 \mathrm{wt} \%$ (with a corresponding increase in the volume fraction of $\mathrm{D}_{2} \mathrm{O}$ from 0.75 to $1.5 \%$ ), indicating that in this dilute solution regime, the use of the Guinier approximation is reasonable. It seems reasonable to assume that the SANS data mainly reflect the core $\left(\mathrm{D}_{2} \mathrm{O}\right)$ dimensions, as the $\mathrm{D}_{2} \mathrm{O}$ scattering length density (SLD) is much higher than the other components (see the Supporting Information for SLD values and additional SANS details). To test this assumption, we performed similar runs with $\mathrm{H}_{2} \mathrm{O}$-swollen surfactants, whereupon $I(0)$ was reduced by over an order of magnitude (e.g., from $\sim 1.6$ $\mathrm{cm}^{-1}$ for Figure $3 \mathrm{~b}$ to $<0.1 \mathrm{~cm}^{-1}$ when swollen with $\mathrm{H}_{2} \mathrm{O}$ ). This confirms that the vast majority of the scattering arises from $\mathrm{D}_{2} \mathrm{O}$, and the corresponding core radii $\left(R=(5 / 3)^{0.5} R_{\mathrm{g}}\right)$ are 34.5 and 44.4 $\AA$ for the particles represented in Figure 3, a and b, respectively. The values are on the order of those reported previously for W/C microemulsions. ${ }^{3 \mathrm{c}-\mathrm{e}, \mathrm{f}, \mathrm{g}, 8} \mathrm{We}$ may estimate the ratio of $(Q=0)$ cross sections shown in Figure 3 (from eq 1$)^{11}$ as $5.2 \pm 0.7$, assuming that the surfactant layer is "invisible" $\left(\rho_{2} \approx \rho_{\mathrm{s}}\right)$, and the scattering arises mainly from the $\mathrm{D}_{2} \mathrm{O}$ core. While the calculated (5.2) and experimental $(1.58 / 0.43=3.7)$ ratios are similar, we believe that the difference is outside the experimental error and that this arises from the neglect of interparticle interactions ${ }^{12,13}$ and also the smaller, but finite, scattering from the surfactant. We are currently undertaking a more detailed analysis of the existing data to account for these factors, and these simulations will be reported at a later date, along with additional data from experiments that are currently in progress.
In summary, anionic phosphate fluorosurfactants can now be included among the family of small molecules capable of stabilizing W/C microemulsions. Surfactants with either two fluorinated chains or one fluorinated chain and one hydrocarbon chain proved effective in dispersing significant water loadings in $\mathrm{CO}_{2}$. Future efforts will further examine the effects of surfactant structure on microemulsion properties and apply the surfactants to the synthesis of nanoparticles within the microemulsion pools.

Acknowledgment. This work was supported by the Kenan Center for the Utilization of Carbon Dioxide in Manufacturing and the STC Program of the National Science Foundation under Agreement CHE-9876674. The research at Oak Ridge was supported by the Division of Materials Sciences, under Contract No. DE-AC05-00OR22725 with the Oak Ridge National Laboratory, managed by UT-Battelle, LLC. SANS experiments were carried out at the KWS-2 facility at Forschungszentrum Jülich. J.S.K., G.D.W., and Y.B.M. thank Professor D. Richter for the hospitality and assistance provided by the staff of the FZJ.

Supporting Information Available: Surfactant synthesis and experimental details of cloud point measurements, UV-vis spectroscopy and SANS (PDF). This material is available free of charge via the Internet at http://pubs.acs.org.

\section{References}

(1) Wells, S. L.; DeSimone, J. Angew. Chem., Int. Ed. 2001, 40, 518.

(2) Consani, K. A.; Smith, R. D. J. Supercrit. Fluids 1990, 3, 51.

(3) (a) Harrison, K.; Goveas, J.; Johnston, K. P.; O'Rear, E. A. Langmuir 1994, 10, 3536. (b) Johnston, K. P.; Harrison, K. L.; Clarke, M. J.; Howdle, S. M.; Heitz, M. P.; Bright, F. V.; Carlier, C.; Randolph, T. W. Science 1996, 271, 624. (c) Eastoe, J.; Bayazit, Z.; Martel, S.; Steytler, D. C.; Heenan, R. K. Langmuir 1996, 12, 1423. (d) Eastoe, J.; Cazelles, B. M. H.; Steytler, D. C.; Holmes, J. H.; Pitt, A. R.; Wear, T. J.; Heenan, R. K. Langmuir 1997, 13, 6980. (e) Zielinski, R. G.; Kline, S. R.; Kaler, E. W.; Rosov, N. Langmuir 1997, 13, 3934. (f) Eastoe, J.; Downer, A.; Paul, A. Steytler, D. C.; Rumsey, E.; Penfold, J.; Heenan, R. K. Phys. Chem. Chem. Phys. 2000, 2, 5235. (g) Lee, C. T., Jr.; Johnston, K. P.; Dai, H. J.; Cochran, H. D.; Melnichenko, Y. B.; Wignall, G. D. J. Phys. Chem. B 2001, 105, 3540. (h) Liu, Z.-T.; Erkey, C. Langmuir 2001, 17, 274. (i) Lee, D.; Hutchison, J. C.; DeSimone, J. M.; Murray, R. M. J. Am. Chem. Soc. 2001, 123, 8406 .

(4) Consani and Smith evaluated mixtures of anionic phosphate surfactants with limited water uptake capability. ${ }^{2}$

(5) Please refer to the Supporting Information for synthetic details and characterization by ${ }^{1} \mathrm{H},{ }^{19} \mathrm{~F}$, and ${ }^{31} \mathrm{P}$ NMR as well as elemental analysis.

(6) Solubility and cloud point measurements were obtained using a stainless steel variable-volume view cell, as described in the Supporting Information. Cloud point is defined here as the reversible onset of a visually fully opaque solution attained by isothermally changing the solution pressure by varying the cell volume.

(7) Depending on temperature and solvent density, small amounts of water dissolve in $\mathrm{CO}_{2}$. For the sake of simplicity, all $W_{0}$ values reported here are based upon the amounts of surfactant and water added to the cell for each experiment and are uncorrected for water's intrinsic solubility in $\mathrm{CO}_{2}$

(8) Lee, C. T., Jr.; Psathas, P. A.; Ziegler, K. J.; Johnston, K. P.; Dai, H. J.; Cochran, H. D.; Melnichenko, Y. B.; Wignall, G. D. J. Phys. Chem. B 2000, 104, 11094.

(9) Clarke, M. J.; Harrison, K. L.; Johnston, K. P.; Howdle, S. M. J. Am. Chem. Soc. 1997, 119, 6399.

(10) Maury, E. E.; Batten, H. J.; Killian, S. K.; Menceloglu, Y. Z.; Combes, J. R.; DeSimone, J. M. Polym. Prepr. (Am. Chem. Soc., Div. Polym. Chem.) 1993, 34, 664.

(11) Wignall, G. D. In Physical Properties of Polymers Handbook; Mark, J. E., Ed.; AIP Press: Woodbury, New York, 1996; p 299. For a particle with a core-shell structure suspended in a solvent, after subtracting the $\mathrm{CO}_{2}$ scattering $\left(\sim 0.04 \mathrm{~cm}^{-1}\right)$, the cross section is given by: $I(Q) \stackrel{=}{=} N_{\mathrm{p}}$ $\left[\left(\rho_{1}-\rho_{\mathrm{s}}\right)\left(V_{\text {tot }}-V_{\mathrm{p}}\right)+\left(\rho_{2}-\rho_{\mathrm{s}}\right)\left(V_{\mathrm{p}}\right)\right]^{2} P(Q)(1)$ where $\rho_{1}, \rho_{2}$ and $\rho_{\mathrm{s}}$ are the scattering length densities (SLDs) of the core, shell and solvent respectively, $N_{\mathrm{p}}$ is the number of particles per unit volume, $V_{\text {tot }}$ and $V_{\mathrm{p}}$ are the total (core plus shell) and core volumes and $P(Q)$ is the particle form factor $[P(0)=1]$.

(12) McClain, J.; Londono, J. D.; Chillura-Martino, D.; Triolo, R.; Betts, D. E.; Canelas, D. A.; Cochran, H. D.; Samulski, E. T.; DeSimone, J. M.; Wignall, G. D. Science 1996 274, 2049.

(13) Triolo, F.; Triolo, A.; Triolo, R.; Londono, J. D.; Wignall, G. D.; McClain, J. B.; Betts, D. E.; Wells, S.; Samulski, E. T.; DeSimone, J. M. Langmuir 2000, 16, 416 .

JA0122142 